\title{
FAKTOR-FAKTOR YANG MEMPENGARUHI CARA MEMANDIKAN BAYI YANG BENAR PADA IBU POST PARTUM
}

\author{
Muthmainnah Zakiyyah ${ }^{1}$ \\ Prodi DIII Kebidanan STIKES Hafshawaty Pesantren Zainul Hasan \\ email: iilira20@gmail.com
}

\begin{abstract}
Abstrak
Memandikan bayi memiliki tantangan tersendiri bagi orang tua terutama bila mereka baru pertama kali mempunyai seorang bayi. Tidak sedikit dari mereka yang tidak tahu bagaimana cara memandikan bayi sehingga mereka menyerahkan bayinya kepada pengasuh atau neneknya. Berdasarkan studi pendahuluan di Desa Pajurangan, pada tanggal 2 September 2019 kepada $10 \mathrm{ibu}$ yang mempunyai bayi usia 0-28 hari. Didapatkan 4 ibu sudah mampu memandikan bayinya sendiri, sedangkan 6 ibu belum berani memandikan bayinya sendiri dikarenakan tali pusat belum lepas dan takut nanti bayinya tergelincir. Tujuan dari penelitian ini adalah untuk mengetahui faktor-faktor yang mempengaruhi cara memandikan bayi yang benar pada ibu post partum di Desa Pajurangan Kecamatan Gending Kabupaten Probolinggo. Desain penelitian yang digunakan adalah analitik. Penelitian ini dilaksanakan pada tanggal 1 September - 30 November 2019. Populasi semua ibu bersalin sebanyak 65. Sampling yaitu total sampling 65 responden. Instrumen ukur menggunakan cek list. Dari hasil uji chi-square dengan sistem 0,000 <0,05. Dengan demikian Ho menolak, H1 diterima, artinya umur, paritas, pendidikan dan dukungan suami/keluarga merupakan faktor yang mempengaruhi cara memandikan bayi yang benar pada ibu post partum. Dari penelitian ini diharapkan bidan memberikan pendidikan kesehatan dan pelatihan cara memandikan bayi yang benar yang bisa dilakukan pada kelas ibu hamil atau pada konseling sebelum pulang dari fasilitas kesehatan.
\end{abstract}

Kata Kunci : Memandikan, Bayi, Ibu, Post Partum

\section{Abstract}

Bathing a baby has its own challenges for parents, especially if it is their first time having a baby. Not a few of them do not know how to bathe the baby so they give their baby to the caregiver or grandmother. Based on a preliminary study in Pajurangan Village, on September 2, 2019, there were 10 mothers who had babies aged 0-28 days. Obtained 4 mothers have been able to bathe their own babies, while 6 mothers have not dared to bathe their own babies because the umbilical cord has not been released and afraid later the baby will slip. The purpose of this study was to determine the factors that influence the correct way to bathe babies in post partum mothers in Pajurangan Village, Gending District, Probolinggo Regency. The research design used is analytic. This research was conducted on 1 September - 30 November 2019. The population of all mothers was 65. Sampling is a total sampling of 65 respondents. The measuring instrument uses a check list. From the results of the chi-square test with a system of 0,000 <0.05. Thus Ho refused, Hl was accepted, meaning that age, parity, education and husband / family support were factors that influenced the correct way of bathing a baby in a post partum mother. From this study midwives are expected to provide health education and training in how to bathe the right baby that can be done in the class of pregnant women or in counseling before returning from a health facility.

Keywords: Bathing, Baby, Mother, Post Partum 


\section{PENDAHULUAN}

Menjadi seorang ibu baru memang tak mudah. Banyak pelajaran baru yang harus perlahan-lahan dipelajari ibu untuk merawat sang buah hati dengan baik. Salah satu pekerjaan yang tergolong banyak ditakuti ibu baru adalah saat harus memandikan bayi. Kondisi fisik

bayi yang masih lemah membuat ibu jadi takut untuk memandikannya (Parker, 2010).

Mandi mempunyai manfaat yang sangat bagus untuk kebersihan dan kesehatan bayi, mandi akan memberikan rasa nyaman bagi tubuh bayi (Parker, 2010). Bayi sering mengalami gangguan pada kulit, diantaranya adalah biang keringat, eksim popok, dan eksim susu.

Dimana masalah-masalah ini bisa diatasi dengan mudah yaitu mandi dengan bersih. Memandikan bayi merupakan upaya yang dilakukan untuk menjaga agar tubuh bayi bersih, terasa segar, dan mencegah kemungkinan adanya infeksi (Hidayat, 2010)

Memandikan bayi memiliki tantangan tersendiri bagi orang tua terutama bila mereka baru pertama kali mempunyai seorang bayi. Tidak sedikit dari mereka yang tidak tahu bagaimana cara memandikan bayi sehingga mereka menyerahkan bayinya kepada pengasuh atau neneknya (Syarif, 2018).

Memandikan bayi baru lahir bukanlah hal yang mudah, terutama bagi ibu baru. Dibutuhkan ekstra hati-hati serta persiapan yang benar agar mandi si kecil tak hanya berjalan lancar namun juga menyenangkan bagi mereka (Priono, 2010).

Berdasarkan studi pendahuluan di Desa Pajurangan, pada tanggal 2 September 2019 kepada 10 ibu yang mempunyai bayi usia $0-28$ hari. Didapatkan 4 ibu sudah mampu memandikan bayinya sendiri, sedangkan 6 ibu belum berani memandikan bayinya sendiri dikarenakan tali pusat belum lepas dan takut nanti bayinya tergelincir.

Bayi yang baru lahir sebaiknya tidak dimandikan dulu walaupun dengan air hangat, karena belum bisa menyesuaikan diri dengan lingkungan barunya. Bayi akan mudah kehilangan panas dan bisa terjadi hipotermi apabila terlalu lama melakukan kontak dengan udara secara langsung tanpa menggunakan alat pelindung. Memandikan bayi dengan cara yang salah dapat mengakibatkan kondisi yang buruk seperti celaka (jatuh dan tenggelam), air masuk ke dalam telinga atau hidung dan dapat mengalami hipotermi (Hidayat, 2010).

Berdasarkan masalah diatas didapatkan bahwa masih banyak ibu yang belum bisa memandikan bayinya secara benar, sehingga kebutuhan pendidikan kesehatan dan pelatihan memandikan bayi sangat dibutuhkan untuk dapat memberikan perawatan bayi sehari-hari, dimana salah satu perawatan bayi sehari-hari adalah memandikan bayi.

Tujuannya agar para Ibu bisa memandikan bayinya dengan benar.

\section{METODE PENELITIAN}

Penelitian ini merupakan penelitian analitik yang menjelaskan hubungan antar variabel dengan menggunakan alat bantu berupa Kuesioner dan cek list untuk mengukur setiap variabel yang diteliti. Rancang bangun penelitian ini adalah cross sectional. Variabel penelitian diukur dalam suatu waktu sehingga diperoleh gambaran keadaan pada waktu tersebut. Penelitian ini dilakukan di Desa Pajurangan. Populasi pada penelitian ini adalah semua ibu bersalin di Desa Pajurangan pada bulan September sampai November 2019 yaitu sebanyak 65 orang. Teknik sampling dalam penelitian ini menggunakan total sampling. Sampel pada penelitian ini adalah Semua ibu bersalin di Desa Pajurangan pada bulan September sampai November 2019 yaitu sebanyak 65 orang. Pengumpulan data dengan menggunakan cek list dan dianalisa dengan chi-square dengan bantuan SPSS.

\section{HASIL DAN PEMBAHASAN}

1. Analisis Univariat

Tabel 1. Distribusi Frekuensi Berdasarkan Cara Memandikan Bayi yang Benar pada Ibu Post Partum

\begin{tabular}{lcc}
\hline Cara Memandikan & Frekuensi & Persentase (\%) \\
\hline Salah & 16 & 25 \\
Benar & 49 & 75 \\
\hline \multicolumn{1}{c}{ Total } & 65 & 100 \\
\hline
\end{tabular}


Tabel 2. Distribusi Frekuensi Berdasarkan Faktor yang Mempengaruhi Cara Memandikan Bayi yang Benar pada Ibu Post Partum

\begin{tabular}{|c|c|c|}
\hline Karakteristik & Frekuensi & Persentase (\%) \\
\hline \multicolumn{3}{|l|}{ Umur } \\
\hline$\leq 20$ tahun & 20 & 31 \\
\hline 21-30 tahun & 31 & 48 \\
\hline 31-40 tahun & 14 & 21 \\
\hline \multicolumn{3}{|l|}{ Paritas } \\
\hline 1 & 30 & 46 \\
\hline$\geq 2$ & 35 & 54 \\
\hline \multicolumn{3}{|l|}{ Pendidikan } \\
\hline Dasar & 43 & 66 \\
\hline Menengah & 20 & 31 \\
\hline Tinggi & 2 & 3 \\
\hline \multicolumn{3}{|c|}{ Dukungan Suami/Keluarga } \\
\hline $\mathrm{Ya}$ & 30 & 46 \\
\hline Tidak & 35 & 54 \\
\hline
\end{tabular}

Berdasarkan hasil penelitian bahwa cara memandikan bayi sebagian besar benar yaitu $75 \%$. Umur ibu post partum sebagian besar usia $21-30$ tahun sebanyak $48 \%$. Paritas sebagian besar $\geq 2$ kali yaitu 54\%. Pendidikan ibu post partum sebagian besar lulusan pendidikan dasar yaitu $66 \%$. Dukungan suami/keluarga tentang cara memandikan bayi yang benar sebagian besar tidak mendukung yaitu $54 \%$.

Salah satu hal mendasar yang perlu diketahui dalam perawatan bayi adalah tentang memandikan bayi. Saat memandikan dan menggantikan popok pada bayi akan memberikan kesempatan pada orang tua untuk banyak memegang dan mengadakan kontak mata dengan bayi (A’tiul, 2016).
Memandikan bayi adalah suatu cara membersihkan tubuh bayi dengan air dengan cara menyiram, merendam diri dalam air berdasarkan urut-urutan yang sesuai. Memandikan bayi baru lahir bukanlah hal yang mudah, terutama bagi ibu baru. Dibutuhkan ekstra hati-hati serta persiapan yang benar agar mandi si kecil tak hanya berjalan lancar namun juga menyenangkan bagi mereka (Naureh, 2010).

Seorang ibu pastinya ingin memberikan sesuatu yang terbaik dalam memberikan makanan, minuman atau segala sesuatu yang lain seperti yang tiap hari dibutuhkan yakni memandikan bayi yang berbeda dengan cara mandi orang dewasa, perlu teknik-teknik khusus yang benar agar bayi mendapatkan manfaat dari mandi.

\section{Analisis Bivariat}

Tabel 3. Hubungan Variabel Independent dengan Cara Memandikan Bayi yang Benar pada Ibu Post Partum

\begin{tabular}{|c|c|c|}
\hline No & Variable Independent & Chi-Square Tests \\
\hline 1. & Umur & ,000 \\
\hline 2. & Paritas & ,000 \\
\hline 3. & Pendidikan & , 000 \\
\hline 4. & Suami/Keluarga & ,000 \\
\hline
\end{tabular}

Analisis uji statistik Chi-Square dengan program SPSS, dengan tingkat kemaknaan 0.05, didapat $\rho<\alpha$, yaitu $0,000<0.05$ yang berarti $\mathrm{H} 1$ diterima, hal ini menunjukkan bahwa umur, paritas, pendidikan dan dukungan suami/keluarga merupakan faktor yang mempengaruhi cara 
memandikan bayi yang benar pada ibu post partum di Desa Pajurangan Kecamatan Gending Kabupaten Probolinggo.

Umumnya setiap orang tua sudah mengetahui tahap - tahap perawatan yang tepat untuk bayinya, akan tetapi tidak demikian bagi pasangan muda. Pada tahap awal, mereka akan kesulitan untuk melakukan perawatan pada bayinya, khususnya memandikan bayi (Dwi, 2017).

Memandikan bayi memiliki tantangan tersendiri bagi orang tua terutama bila mereka baru pertama kali mempunyai seorang bayi. Tidak sedikit dari mereka yang tidak tahu bagaimana cara memandikan bayi sehingga mereka menyerahkan bayinya kepada pengasuh atau neneknya (Hidayat, 2010).

Memandikan bayi itu bisa dibilang mudah dan bisa dibilang sulit. Hal ini dipengaruhi oleh pengalaman (paritas) dan usia. Dalam penelitian ini usia yang paling banyak adalah $21-30$ tahun dan paritas sebagian besar $\geq 2$. Pada usia tersebut seorang wanita sudah dewasa dan sudah siap untuk memandikan bayi secara mandiri. Paritas $\geq 2$ kali sudah punya pengalaman memandikan bayi dari anak sebelumnya baik secara observasi maupun melakukan sendiri memandikan bayinya. Namun untuk cara memandikan bayinya benar atau salah itu tergantung dari pendidikan sang ibu. Pendidikan ibu sebagian besar berpendidikan dasar, hal ini membuktikan bahwa teknik memandikan bayi yang benar belum dipahami ibu. Ibu hanya memandikan bayinya sesuai dengan pengalaman saja dan tidak dibekali pengetahuan tentang teknik memandikan bayi yang benar. Sehingga masih banyak ibu bisa memandikan bayinya secara mandiri namun teknik memandikannya yang salah.

\section{KESIMPULAN DAN SARAN}

\section{* Kesimpulan}

Sebagian besar ibu post partum benar dalam cara memandikan bayi di Desa Pajurangan Kecamatan Gending Kabupaten Probolinggo yaitu $75 \%$.

Sebagian besar umur ibu post partum yaitu 21-30 tahun di Desa Pajurangan Kecamatan Gending Kabupaten Probolinggo sebanyak 48\%.
Sebagian besar paritas ibu post partum yaitu $\geq 2$ kali di Desa Pajurangan Kecamatan Gending Kabupaten Probolinggo sebanyak 54\%.

Sebagian besar pendidikan ibu post partum di Desa Pajurangan Kecamatan Gending Kabupaten Probolinggo yaitu pendidikan dasar sebanyak $66 \%$.

Sebagian besar ibu post partum di Desa Pajurangan Kecamatan Gending Kabupaten Probolinggo mendapatkan dukungan dari suami/keluarga dalam memandikan bayinya sebanyak 54\%.

Berdasarkan hasil uji korelasi Chi-Square dengan program SPSS, didapat $\rho<\alpha$, yaitu $0,000<$ 0.05 , yang berarti umur, paritas, pendidikan dan dukungan suami/keluarga merupakan faktor yang mempengaruhi cara memandikan bayi yang benar pada ibu post partum di Desa Pajurangan Kecamatan Gending Kabupaten Probolinggo.

\section{* Saran}

Pendidikan kesehatan dan pelatihan memandikan bayi sangat diperlukan oleh ibu post partum terutama ibu primipara. Oleh sebab itu, sebaiknya bidan memberikan pendidikan kesehatan dan pelatihan cara memandikan bayi yang benar yang bisa dilakukan pada kelas ibu hamil atau pada konseling sebelum pulang dari fasilitas kesehatan

Perlu dilakukan penelitian lebih lanjut tentang topik cara memandikan bayi yang benar dengan kriteria lebih terstandar sesuai dengan kemajuan teknologi.

Untuk ibu post partum, tingkatkan pengetahuan dan keterampilan cara memandikan bayi yang benar supaya tercipta hubungan yang erat antara ibu dan bayi.

\section{REFERENSI}

Ati'ul, Impartina. (2016). Pemberian Motivasi Terhadap Kemampuan Memandikan Bayi Pada Ibu Nifas. Rakernas Aipkema : 30 - 33

Dwi, Lukmawati. (2017). Pengaruh Penyuluhan Memandikan Bayi Terhadap Cara Ibu Dalam Memandikan Bayinya Di Desa Sumberejo Kecamatan Gampengrejo Kabupaten Kediri. JuKe

Hidayat, Aziz. (2010). Asuhan Neonatus, Bayi dan Balita. EGC. Jakarta. 
Muthmainnah Zakiyyah, Faktor-faktor yang mempengaruhi cara memandikan bayi yang benar pada ibu post partum

Naureh. (2010). Penuntun Praktikum Asuhan Kehamilan. Fitramaya Lee. Yogyakarta.

Parker, Catharine. (2010). Konsultasi Kebidanan. Erlangga. Jakarta.

Priono, Yunisa. (2010). Merawat Bayi tanpa Babby Sitter. Buku Kita. Jakarta.

Syarif, dkk. (2018). Perilaku Ibu Dalam Memandikan Bayi Baru Lahir Di Kecamatan Ulumanda Kabupaten Majene. Jurnal Penelitian Kesehatan Suara Forikes. 